\title{
The Effectiveness of Hyperlipidemia Prevention Intervention Designed to Affect Behavior Change: Focus on Changes in Health Behavior
}

\author{
Hisako Izumi ${ }^{*}$, Michiko Mastubara², Kazuko Saeki ${ }^{3}$, Hiromi Imuta ${ }^{4}$, Mitsuru Mori ${ }^{5}$ \\ ${ }^{1}$ School of Health Sciences, Sapporo Medical University, Sapporo, Japan \\ ${ }^{2}$ Faculty of Health Sciences, Hokkaido University of Science, Sapporo, Japan \\ ${ }^{3}$ Faculty of Health Sciences, Hokkaido University, Sapporo, Japan \\ ${ }^{4}$ Faculty of Health Sciences, Tokyo Metropolitan University, Tokyo, Japan \\ ${ }^{5}$ School of Medicine, Sapporo Medical University, Sapporo, Japan \\ Email: ${ }^{*}$ hisako@sapmed.ac.jp
}

Received 30 October 2014; revised 29 November 2014; accepted 8 December 2014

Academic Editor: Modupe O. Oyetunde, Department of Nursing, College of Medicine, University of Ibadan, Ibadan, Nigeria

Copyright (C) 2014 by authors and Scientific Research Publishing Inc.

This work is licensed under the Creative Commons Attribution International License (CC BY).

http://creativecommons.org/licenses/by/4.0/

c) (i) Open Access

\begin{abstract}
Hyperlipidemia prevention intervention for behavior change was conducted on subjects in their $30 \mathrm{~s}$ and $40 \mathrm{~s}$ to evaluate changes in health behavior and investigate the effectiveness of these changes, with respect to early prevention and improvement of disease. Subjects were middle-aged individuals aged 30 - 49, suffering from serum lipid abnormalities. Intervention designed to affect behavior change was implemented for 3 weeks in 11 employees (nine males, two females) at five workplaces. Intervention mainly consisted of improving self-efficacy. The study's purpose was explained and the written consent was obtained from subjects. Subjects filled questionnaires (characteristics, history of present illness, health behavior, self-efficacy scale for prevention of hyperlipidemia, etc.) both before and after intervention. Subjects recorded their physical activity using accelerometers and dietary intake photographically. Each subject created realistic behavior goals and recorded their progress using self-monitoring charts. Data were analyzed using descriptive statistics; therefore, pre- and post-intervention data were compared. Physical activity and achievement rate of goals during the first week and over the next 2 - 3 weeks were compared. Health behavior scores showed modification of behavior in a desirable direction after interven-
\end{abstract}

*Corresponding author.

How to cite this paper: Izumi, H., Mastubara, M., Saeki, K., Imuta, H. and Mori, M. (2014) The Effectiveness of Hyperlipidemia Prevention Intervention Designed to Affect Behavior Change: Focus on Changes in Health Behavior. Open Journal of Nursing, 4, 962-970. http://dx.doi.org/10.4236/ojn.2014.413103 
tion compared with those before intervention. No significant difference in self-efficacy before and after intervention was observed. However, the subscale for diet was significantly higher after intervention compared with that before intervention. Steps, total calories, and activity calories were increased in the second and third weeks compared with those in the first week. Three weeks of intervention resulted in health behavior changing in a desirable direction. We infer that intervention in the form of self-monitoring using accelerometers that make physical activity visible was effective in leading to behavior change.

\section{Keywords}

\section{Hyperlipidemia Prevention, Middle Age, Health Behavior, Self-Efficacy, Behavior Change}

\section{Introduction}

Hyperlipidemia is a risk factor for ischemic heart disease [1] [2]. In Japan, the number of patients with ischemic heart disease is increasing; indicating that prevention of coronary artery disorders is an important issue [3]. Hyperlipidemia is the most frequently detected illness in workplace medical examinations [4], making its prevention an important issue.

Initiatives being implemented as a part of health care in communities and workplaces to prevent hyperlipidemia have traditionally consisted of health education designed to affect behavior changes in people's lifestyles (diet and exercise). The theories of behavioral science have been applied to health education designed to affect behavior change [5]-[8]. The concept of "self-efficacy" that was proposed by Bandura (1977) within his social cognitive theory is the patient's expectation of whether they will be able to successfully carry out a behavior [9]. Increasing self-efficacy is an important part of encouraging behavior change. Self-efficacy is also a key concept in the trans-theoretical model, a behavioral science model [10].

Previous studies of the correlation between lifestyle and self-efficacy conducted in the United States since the 1980s have investigated the self-efficacy of desirable healthy behaviors as well as ceasing unhealthy behaviors. One such study elucidated the correlation between self-efficacy and changes in diet that lead to decreased serum cholesterol [11]. Other studies indicated that self-efficacy is an important factor related to physical activity [12] [13]. A study by Angotti et al. indicated that intervention in both diet and exercise designed to decrease serum cholesterol was effective [14]. Therefore, it is necessary to implement intervention focused on self-efficacy to verify the effectiveness of behavior change designed to prevent hyperlipidemia. We also believe that it is important to provide intervention designed to prevent hyperlipidemia at an early stage for middle-aged individuals.

The purpose of the present study was to provide middle-aged subjects aged 30 - 49 intervention designed to affect behavior change to prevent hyperlipidemia from the perspective of early prevention and improvement of disease and investigate the effectiveness when this intervention is focused on changes in health behavior.

\section{Methods}

\subsection{Subjects}

Subjects were employees aged 30 - 49 employed in Hokkaido, Japan whose medical examination results indicated that they required guidance or medical treatment for hyperlipidemia. Intervention was provided from March 2009 to April 2009 to 12 participants from five workplaces who agreed to cooperate in this study. "Requiring guidance" and "requiring medical treatment" are indicated when one or more of the following apply: 1) Total cholesterol (TC) level is $220 \mathrm{mg} / \mathrm{dl}$ or above or LDL cholesterol (LDL-C) is $140 \mathrm{mg} / \mathrm{dl}$ or above; 2) Triglyceride (TG) levels are $150 \mathrm{mg} / \mathrm{dl}$ or above; 3) HDL cholesterol (HDL-C) is $40 \mathrm{mg} / \mathrm{dl}$ or below. Those already receiving medication for hyperlipidemia and diabetes patients were exempted.

\subsection{Intervention for the Purpose of Prevention of Hyperlipidemia}

\subsubsection{Framework and Components of Intervention}

The intervention incorporated the techniques of self-monitoring and small step method to obtain four major 
sources of information that improve self-efficacy: Enactive Mastery Experience, Vicarious Experience, Verbal Persuasion, and Physiological and Affective State. The program was based on individual health education that was provided three times over the course of 3 weeks. The intervention period is shortened in order to reduce the omission of participants. We set the period in reference to a short-term intervention study [15].

Health behaviors designed to prevent hyperlipidemia were diet, exercise, maintenance of appropriate weight, and self-management, which were based on the Guidelines for Prevention of Atherosclerotic Cardiovascular Diseases [16] and other guidelines. The components of health education included reducing intake of total calories and animal fats, switching to low-fat foods, increasing physical activity, regularly monitoring weight, and creating and working toward individual goals. Monitoring reports via email and fax for the purpose of making them simple and easy to submit on a continuous basis was also included. These reports made it possible to achieve behaviors and provide verbal persuasion of these achievements. An overview of intervention is provided in Figure 1.

\subsubsection{Goals of Intervention}

Intervention had four goals: 1) Motivation for health behaviors designed to prevent hyperlipidemia; 2) Understanding of specific health behavior skills; 3) Improvement of self-efficacy for health behaviors; and 4) Implementation of health behaviors.

\subsection{Data Collection}

\subsubsection{Pre- and Post-Intervention Questionnaires}

Subjects filled out self-administered questionnaires both before and after intervention. The questionnaires contained questions regarding characteristics such as sex, age, marital status, cohabitant family members, educational background, and medical history. We obtained TC levels, LDL-C levels, TG levels, and HDL-C levels from subjects' health care medical records. Body mass index (BMI) was calculated using subjects' self-reported weight and height figures.

We used the scale created by Tohnai et al. (1994) [17], which consists of 13 items related to diet, exercise, rest, and alcohol and tobacco use behaviors to measure health behavior. The answers were scored as follows: "Practicing" was 2 points, "Practicing sometimes" was 1 point, and "Not practicing” was 0 point. The maximum score was 26, and the minimum score was 0 .

We measured self-efficacy using "The self-efficacy scale for prevention of hyperlipidemia (SESPHL)" which consists of 16 items developed in a previous study [18]. SESPHL consists of the following three subscales: "Active modification of eating" (eating SE), "exercise and activity modification without impossibility" (activity SE), and "foundation of behavior modification" (foundation SE). This scale has been confirmed to have a Cronbach's alpha of 0.855 and has both reliability and validity. Answers to each item are chosen from the following four

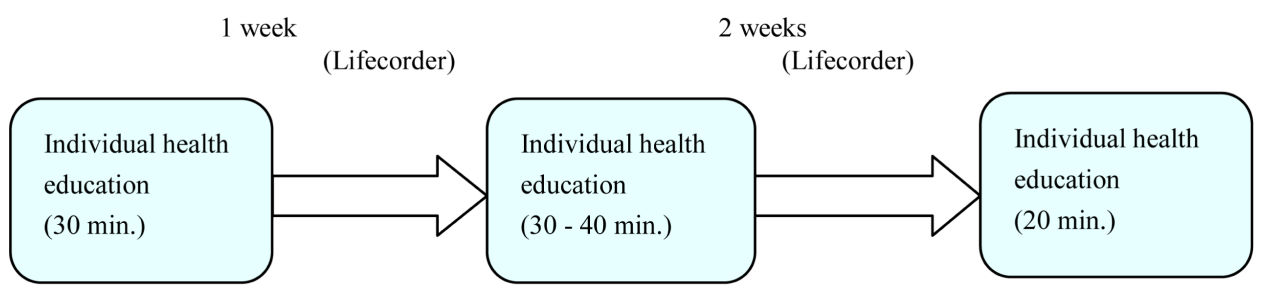

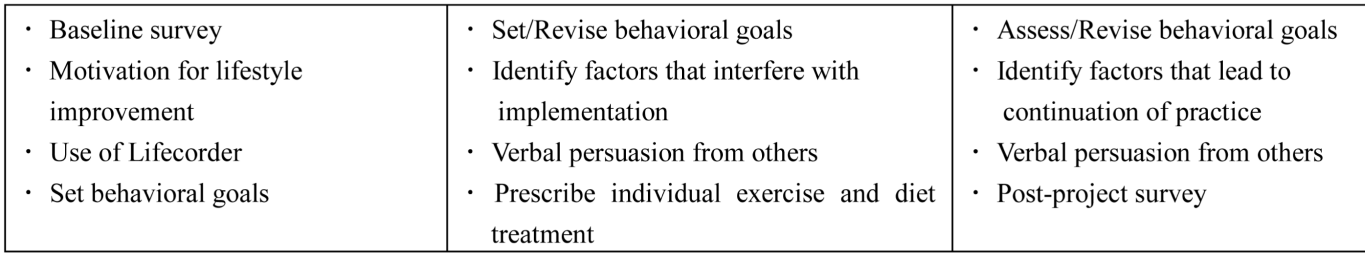

Self-monitoring

Reporting and advice via e-mail, telephone, and fax

Figure 1. Program progress over 3 weeks. 
selections: “Agree,” “Agree somewhat,” "Disagree somewhat,” and "Disagree.” These are scored in order from the highest to the lowest SE and assigned 4, 3, 2, or 1 point. The maximum score was 160, and the minimum score was 40 .

\subsubsection{Data Collection during Intervention}

Physical activity: During the 3 weeks of program participation, physical activity was monitored by measuring steps, total calories, and activity calories using accelerometers (Lifecorder, Suzuken, Nagoya, Japan).

Dietary intake: Subjects recorded their dietary intake photographically while participating in the program (meal recording method). Participants who indicated reducing energy intake as one of their goals continued recording their dietary intake photographically after the program was concluded.

Self-monitoring chart: Each individual established goals toward behavior change. They recorded their progress in self-monitoring charts. The template is used to format your paper and style the text. All margins, column widths, line spaces, and text fonts are prescribed; please do not alter them. You may note peculiarities. For example, the head margin in this template measures proportionately more than is customary. This measurement and others are deliberate, using specifications that anticipate your paper as one part of the entire journals, and not as an independent document. Please do not revise any of the current designations.

\subsection{Data Analysis}

Of the 12 subjects who participated in this study, data from 11, excluding one participants whose eating and exercise habits changed dramatically due to a business trip, were analyzed. Due to the small sample size, a nonparametric test was utilized. For characteristics, descriptive statistics were used for history of present illness and health history, and the Wilcoxon signed-rank test was used on pre- and post-intervention BMI, health behavior, and SESPHL. The rate of goal attainment for steps, total calories, and activity calories during the first, second, and third weeks of intervention was converted to medians, and the Wilcoxon signed-rank test was applied to these medians. Energy intake was calculated using nutrition calculation software (BASIC-4 for Windows, Kagawa Nutrition University Publishing Division, Tokyo, Japan) on the basis of intake amounts estimated from each day's photographs. The achievement rate of goals was calculated on the basis of self-monitoring charts.

The statistical software SPSS Statistics ver. 21 for Windows (IBM) was used to perform statistical analyses. A p-value less than $5 \%$ was considered as statistically significant.

\subsection{Ethical Considerations}

This study was conducted with the approval of the ethics committee of Sapporo Medical University. Consent was obtained from workplace managers after providing them with both written and oral overviews of the study. Participants were also provided with both written and oral overviews of the study, and their written consent was obtained before intervention was initiated. The researchers assured participants that they could refuse to participate or interrupt participation at any stage of the study. Participants were also assured that the data obtained via this study would not be used for any purpose other than the study and that protecting the privacy of participants was the researchers' paramount concern.

\section{Results}

\subsection{Participants' Characteristics}

Nine participants (81.8\%) were male and two (18.2\%) were female. Mean age was $42.3 \pm 0.41$ years. Nine participants (81.8\%) were married and ten (90.9\%) cohabited with family members. Educational background indicated that eight participants (72.7\%) had a college or graduate school education. Four participants (33.3\%) had a history of present illness (Table 1 ).

The average levels of participants' serum lipids were as follows: TC was $245.3 \mathrm{mg} / \mathrm{dl}, \mathrm{LDL}-\mathrm{C}$ was $156.9 \mathrm{mg} /$ dl, TG was $108.8 \mathrm{mg} / \mathrm{dl}$, and HDL-C was $56.6 \mathrm{mg} / \mathrm{dl}$.

\subsection{Pre- to Post-Intervention Changes}

Median pre-intervention BMI was $26.0 \mathrm{~kg} / \mathrm{m}^{2}$, and median post-intervention BMI was $25.4 \mathrm{~kg} / \mathrm{m}^{2}$, indicating no statistically significant difference $(\mathrm{p}=0.306)$. The median pre-intervention health behavior score was 8.0 , and 
Table 1. Characteristics of participants $(\mathrm{N}=11)$.

\begin{tabular}{|c|c|c|c|}
\hline & & $\mathrm{n}$ & $\%$ \\
\hline \multirow{2}{*}{ Gender } & Males & 9 & 81.8 \\
\hline & Females & 2 & 18.2 \\
\hline Age (year old) & Mean \pm Standard deviation & $42.3 \pm 0.41$ & \\
\hline \multirow{2}{*}{ Marital status } & Married & 9 & 81.8 \\
\hline & Unmarried & 2 & 18.2 \\
\hline \multirow{2}{*}{ Living with family } & Yes & 10 & 90.9 \\
\hline & No & 1 & 9.1 \\
\hline \multirow{3}{*}{ Level of education } & High school & 2 & 18.2 \\
\hline & Vocational & 1 & 9.1 \\
\hline & Degree or higher & 8 & 72.7 \\
\hline \multirow{2}{*}{ History of present illness } & Yes & 4 & 36.4 \\
\hline & No & 7 & 63.6 \\
\hline
\end{tabular}

the median post-intervention health behavior score was 15.0, indicating a significant improvement in behavior change $(\mathrm{p}=0.012)($ Table 2$)$.

As indicated in Table 3, a significant change between pre- and post-intervention health behavior items "drink $200 \mathrm{ml}$ of milk per day" and "reduce the amount of animal fats" ( $p=0.046, p=0.034)$ was observed. No significant differences were observed for any other items.

Median pre-intervention SESPHL was 41, and median post-intervention SESPHL was 45, indicating an increasing trend, although it was not statistically significant $(\mathrm{p}=0.139)$. However, significant increases were observed in the post-intervention subscale of "eating SE" $(p=0.046)$ (Table 2).

\subsection{Changes during Intervention}

Physical activity: Average steps, as a measure of physical activity, increased significantly in the second and third week compared with those in the first week $(\mathrm{p}=0.008)$. Similarly, average of total calories and activity calories showed significant increases in the second and third weeks compared with those in the first week $(\mathrm{p}=$ 0.033, $\mathrm{p}=0.021)($ Table 4).

Dietary intake: The average energy intake of participants through meals and snacks between meals was 1862.9 kcal (range: 1230 - $2937 \mathrm{kcal}$ ). Seven subjects who indicated that reducing energy intake was one of their goals reduced intake on an average of $326.1 \mathrm{kcal}$ (range: 80 - $656 \mathrm{kcal}$; not shown in the table).

Goal establishment and achievement: Each participants established two or three goals that were possible to attain. In particular, the diet-related goals included "Have only one bowl of rice." "Try to have two servings of vegetables." and "Reduce snacks by half." and exercise-related goals included "Walk at least 8000 steps per day." and "Walk a distance equivalent to one subway stop." Self-management behaviors included "Weigh myself every day." Goal achievement rates increased, but these increases were not statistically significant $(\mathrm{p}=0.197)$ (Table 4).

\section{Discussion}

Three weeks of intervention led to changes in health behavior in a desirable direction. The pre-intervention health behavior scores of participants in this study were lower than those of subjects in previous studies [17]. The behavior change of reducing intake of animal fat was observed. The behavior change of drinking $200 \mathrm{ml}$ of milk resulted from recommending low-fat milk as a part of individual health education. When total energy intake is restricted, serum cholesterol levels and serum triglyceride levels both decrease [19]. Saturated fatty acids included in large amounts in animal fats have been shown in previous studies to increase LDL cholesterol [20] [21]. Therefore, it is important that dietary treatment of hyperlipidemia focuses not only on correcting serum lipid levels but also on preventing arteriosclerotic diseases.

In this study, 81.8\% of participants were males. In Japanese households, the percentages of those who prepare meals are wives, $89.7 \%$; husbands, $1.4 \%$; and all family members, $6.0 \%$ [22]. Because most participants in this study had spouses or cohabiting with family members, we assume that they had assistance from family members. It has been reported that family members recommending behavior change acts as motivation [23]. Thus, when 
Table 2. Change in Body Mass Index, Health Behavior and SEPHL ( $\mathrm{N}=11)$.

\begin{tabular}{cccc}
\hline & Pretest & Posttest & \multirow{2}{*}{ P-Value } \\
\cline { 2 - 3 } & Median & $\begin{array}{c}\text { Median } \\
(25-75 \text { percentile })\end{array}$ & \\
BMI $\left(\mathrm{Kg} / \mathrm{m}^{2}\right)$ & 26 percentile $)$ & 25.4 & 0.306 \\
Health Behavior Score & $(22.8-26.5)$ & $(22.8-26.5)$ & 0.012 \\
SEPHL & 8 & 15 & 0.139 \\
Eating SE & $(7.0-12.0)$ & $45-16$ & 0.046 \\
Activity SE & 41 & $(39-48)$ & \\
Foundation SE & $(33-47)$ & $(12-17)$ & 0.371 \\
\hline
\end{tabular}

Wilcoxon signed-rank test.

\section{Table 3. Change in health behavior items $(\mathrm{N}=11)$.}

\begin{tabular}{|c|c|c|c|c|c|c|}
\hline \multirow{2}{*}{ Health Behavior Items } & & \multicolumn{2}{|c|}{ Pretest } & \multicolumn{2}{|c|}{ Posttest } & \multirow{2}{*}{ P-Value } \\
\hline & & $\mathrm{n}$ & $\%$ & $\mathrm{n}$ & $\%$ & \\
\hline \multirow{3}{*}{ Taking regular meals } & Yes & 1 & 9.1 & 3 & 27.3 & \multirow{3}{*}{0.059} \\
\hline & Sometime & 5 & 45.5 & 6 & 54.5 & \\
\hline & No & 5 & 45.5 & 2 & 18.2 & \\
\hline \multirow{3}{*}{ Eating vegetables } & Yes & 4 & 36.4 & 4 & 36.4 & \multirow{3}{*}{0.739} \\
\hline & Sometime & 5 & 45.5 & 6 & 54.5 & \\
\hline & No & 2 & 18.2 & 1 & 9.1 & \\
\hline \multirow{3}{*}{ Drinking 200ml of milk everyday } & Yes & 1 & 9.1 & 3 & 27.3 & \multirow{3}{*}{0.046} \\
\hline & Sometime & 3 & 27.3 & 3 & 27.3 & \\
\hline & No & 7 & 63.6 & 5 & 45.5 & \\
\hline \multirow{3}{*}{ Avoiding saccharide } & Yes & 1 & 9.1 & 3 & 27.3 & \multirow{3}{*}{0.257} \\
\hline & Sometime & 7 & 63.6 & 6 & 54.5 & \\
\hline & No & 3 & 27.3 & 2 & 18.2 & \\
\hline \multirow{3}{*}{ Avoiding salty food } & Yes & 1 & 9.1 & 1 & 9.1 & \multirow{3}{*}{0.157} \\
\hline & Sometime & 2 & 18.2 & 4 & 36.4 & \\
\hline & No & 8 & 72.7 & 6 & 54.5 & \\
\hline \multirow{3}{*}{ Refraining from drinking } & Yes & 6 & 54.5 & 7 & 63.6 & \multirow{3}{*}{0.102} \\
\hline & Sometime & 1 & 9.1 & 3 & 27.3 & \\
\hline & No & 4 & 36.4 & 1 & 9.1 & \\
\hline \multirow{3}{*}{ Refraining from snacks and midnight snacks } & Yes & 3 & 27.3 & 5 & 45.5 & \multirow{3}{*}{0.119} \\
\hline & Sometime & 3 & 27.3 & 5 & 45.5 & \\
\hline & No & 5 & 45.5 & 1 & 9.1 & \\
\hline \multirow{3}{*}{ Avoiding animal fat } & Yes & 1 & 9.1 & 1 & 9.1 & \multirow{3}{*}{0.034} \\
\hline & Sometime & 2 & 18.2 & 8 & 72.7 & \\
\hline & No & 8 & 72.7 & 2 & 18.2 & \\
\hline \multirow{3}{*}{ No smoking } & Yes & 8 & 72.7 & 8 & 72.7 & \multirow{3}{*}{1.000} \\
\hline & Sometime & 1 & 9.1 & 1 & 9.1 & \\
\hline & No & 2 & 18.2 & 2 & 18.2 & \\
\hline \multirow{3}{*}{ Sleeping more than seven hours } & Yes & 0 & 0.0 & 0 & 0.0 & \multirow{3}{*}{0.317} \\
\hline & Sometime & 5 & 45.5 & 7 & 63.6 & \\
\hline & No & 6 & 54.5 & 4 & 36.4 & \\
\hline \multirow{3}{*}{ Relaxing on holidays } & Yes & 3 & 27.3 & 2 & 18.2 & \\
\hline & Sometime & 2 & 18.2 & 5 & 45.5 & 0.564 \\
\hline & No & 6 & 54.5 & 4 & 36.4 & \\
\hline & Yes & 1 & 9.1 & 1 & 9.1 & \\
\hline Resting whenever feeling physical or mental fatigue & Sometime & 9 & 81.8 & 10 & 90.9 & 0.317 \\
\hline & No & 1 & 9.1 & 0 & 0.0 & \\
\hline & Yes & 0 & 0.0 & 0 & 0.0 & \\
\hline Exercising everyday & Sometime & 1 & 9.1 & 4 & 36.4 & 0.083 \\
\hline & No & 10 & 90.9 & 7 & 63.6 & \\
\hline
\end{tabular}

Wilcoxon signed-rank test. 
Table 4. Change of physical activity and performance rate of the tasks during the intervention $(\mathrm{N}=11)$.

\begin{tabular}{cccc}
\hline & Average of the first week & Average of the second and the third week & P-Value \\
\cline { 2 - 3 } & Median & Median & \\
& $(25-75$ percentile $)$ & $(25-75$ percentile $)$ & 0.008 \\
Steps (per day) & 6113.9 & 8550.8 & 0.033 \\
Total calories (kcal) & $(5211.3-9408.0)$ & $(5923.9-10643.3)$ & 0.021 \\
Activity calories (kcal) & 2260.0 & 2393.7 & 325.6 \\
\multirow{2}{*}{ Achievement rate of the goals (\%) } & $(2037.2-2594.2)$ & $(162.8-471.9)$ & 0.197 \\
\hline
\end{tabular}

Wilcoxon signed-rank test.

implementing intervention for males in Japan, support from spouses and family members who prepare meals is necessary.

Steps, total calories, and activity calories showed significant increase after intervention. It has been shown that assessment of physical activity via accelerometer results in no difference in the average value when monitored for 21 days compared with when monitored for one week [24]. It has further been shown that assessments of an individual's physical activity are fairly accurate when monitored using an activity monitor (pedometer or accelerometer) for approximately 1 week [25]. It has also been reported that wearing an accelerometer leads to increased number of steps [26]. Therefore, we believe that the fact that participants of this study wore accelerometers generated motivation, making their physical activity visible, and self-monitoring led to increase in steps and activity calories. Physical activity results in decreased triglycerides and increased HDL-C [27]. Because increase in physical activity lead to restricted total energy intake, it probably result in improvement of lipid abnormalities. In addition to changes in health behavior, comparative study must also be done of serum lipid levels.

The fact that participants in this study did not show statistically significant self-efficacy was probably due to the small sample size. Post-intervention diet-related self-efficacy showed significant increases, which suggests that the components designed to improve self-efficacy were functioning.

BMI may not have been an appropriate index to measure the effectiveness of 3 weeks of intervention. Intervention led to clear increase in physical activity. However, it did not lead to calorie levels that would result in weight loss. A longer period of intervention is probably necessary.

Studies have indicated that intervention implemented as a part of workplace health programs that combines exercise and diet to reduce the risk of coronary artery disorders is effective [28] [29]. In the present study, subjects established goals in accordance with their personal wishes. Subjects who set diet-related goals reduced calories. This suggests that it is important to support the establishment of both exercise and diet goals.

\section{Conclusion}

Three weeks of intervention led to health behavior changing in a desirable direction. We believe that elements including self-monitoring using accelerometers that made physical activity visible in this intervention made it effective in causing behavior change.

\section{Limitations}

A limitation of this study was the quasi-experimental design, which created a lack of randomization in the study. Small sample size and use of convenience samples are also limitations and thus affect generalizability of results.

Future studies should assess the long-term effects of such intervention in improving serum lipid levels and leading to continuous lifestyle improvements.

\section{Acknowledgements}

We express thanks to the participants for accepting to be intervention. This study was supported by Grant-inAid for Scientific Research from Japan Society for the Promotion of Science. 


\section{References}

[1] Iwashita, M., Matsushita, Y., Sasaki, J., Arakawa, K. and Kono, S., and for the Kyushu Lipid Intervention Study (KLIS) Group (2004) Relation of Serum Total Cholesterol and Other Risk Factors to Risk of Coronary Events in Middle-Aged and Elderly Japanese Men with Hypercholesterolemia: The Kyushu Lipid Intervention Study. Circulation Journal, 68, 405-409. http://dx.doi.org/10.1253/circj.68.405

[2] Washio, M., Sasazuki, S., Kodama, H., Yoshimasu, K., Liu, Y., Tanaka, K., Tokunaga, S., Kono, S., Arai, H., Koyanagi, S., Hiyamuta, K., Doi, Y., Kawano, T., Nakagaki, O., Takada, K., Nii, T., Shirai, K., Ideishi, M., Arakawa, K., Mohri, M. and Takeshita, A. (2001) Role of Hypertension, Dyslipidemia and Diabetes Mellitus in the Development of Coronary Atherosclerosis in Japan. Japanese Circulation Journal, 65, 731-737.

http://dx.doi.org/10.1253/jcj.65.731 https://www.jstage.jst.go.jp/article/jcj/65/8/65 8 731/ article

[3] NIPPON DATA80 Research Group (2006) Risk Assessment Chart for Death From Cardiovascular Disease Based on a 19-Year Follow-Up Study of a Japanese Representative Population: NIPPON DATA80. Circulation Journal, 70, 12491255. http://dx.doi.org/10.1253/circj.70.1249 https://www.jstage.jst.go.jp/article/circj/70/10/70_10_1249/_pdf

[4] Health, Labour and Welfare Statistics Association (2009) Act 7 “Occupational Health”. Journal of Health and Welfare Statistics, 60, 305-307.

[5] Condiotte, M.M. and Lichtenstein, E. (1981) Self-Efficacy and Relapse in Smoking Cessation Programs. Journal of Consulting and Clinical Psychology, 49, 648-658. http://dx.doi.org/10.1037/0022-006X.49.5.648

[6] DiClememte, C.C. (1981) Self-Efficacy and Smoking Cessation Maintenance: A Preliminary Report. Cognitive Therapy and Research, 5, 175-187. http://dx.doi.org/10.1007/BF01172525

[7] Duncan, T.E. and McAuey, E. (1993) Social Support and Efficacy Cognitions in Exercise Adherence: A Latent Growth Curve Analysis. Journal of Behavioral Medicine, 16, 199-218. http://dx.doi.org/10.1007/BF00844893

[8] Natarajan, S., Clyburn, E.B. and Brown, R.T. (2002) Association of Exercise Stages of Change with Glycemic Control in Individuals with Type 2 Diabetes. American Journal of Health Promotion, 17, 72-75. http://dx.doi.org/10.4278/0890-1171-17.1.72

[9] Bandura, A. (1977) Self-Efficacy: Toward a Unifying Theory of Behavioral Change. Psychological Review, 84, 191215. http://dx.doi.org/10.1037/0033-295X.84.2.19

[10] Glanz, K., Rimer, B.K. and Lewis, F.M. (2002) Health Behavior and Health Education: Theory, Research, and Practice. 3rd Edition, Jossey-Bass, Hoboken, 99-120.

[11] McCann, B.S., Bovbjerg, V.E., Brief, D.J., Turner, C., Follette, W.C., Fitzpatrik, V., Dowdy, A., Retzlaff, B., Walden, C.E. and Knopp, R.H. (1995) Relationship of Self-Efficacy to Cholesterol Lowering and Dietary Change in Hyperlipidemia. Annals of Behavioral Medicine, 17, 221-226. http://dx.doi.org/10.1007/BF02903916

[12] Masse, L.C. and Anderson, C.B. (2003) Ethnic Differences among Correlates of Physical Activity in Women. American Journal of Health Promotion, 17, 357-360. http://dx.doi.org/10.4278/0890-1171-17.6.357

[13] Juniper, K.C., Oman, R.F., Hamm, R.M. and Kerby, D.S. (2004) The Relationships Among Constructs in the Health Belief Model and Transtheoretical Model Among African-American College Women for Physical Activity. American Journal of Health Promotion, 18, 354-357. http://dx.doi.org/10.4278/0890-1171-18.5.354

[14] Angotti, C.M., Chan, W.T., Sample, C.J. and Levine, M.S. (2000) Combined Dietary and Exercise Intervention for Control of Serum Cholesterol in the Workplace. American Journal of Health Promotion, 15, 9-16. http://dx.doi.org/10.4278/0890-1171-15.1.9

[15] De Cocke, K.A., De Bourdeaudhuij, I.M. and Cardon, G.M. (2008) The Effect of Pedometer Use in Combination with Cognitive and Behavioral Support Materials to Promote Physical Activity. Patient Education and Counseling, 70, 209214. http://www.10000stappen.be/LinkClick.aspx?fileticket=c_qdtbdQ2fs=\&tabid=2546

[16] Japan Atherosclerosis Society (2007) Japan Atherosclerosis Society (JAS) Guidelines for Prevention of Atherosclerotic Cardiovascular Diseases Ver2007. Japan Atherosclerosis Society, Tokyo, 1-13.

[17] Tohnai, S. and Hata, E. (1994) Factors Affecting Health Behavior of the People Aged Forties—A Test of Health Belief Model. Japanese Journal of Public Health, 41, 362-369.

[18] Izumi, H., Saeki, K., Imuta, H. and Mori, M. (2007) Development of a Self-Efficacy Scale and Intervention Program for Prevention of Hyperlipidemia in Adults in Their 30s and 40s. Journal of Japan Academy of Community Health Nursing, 9, 7-14.

[19] Katzel, L.I., Bleecker, E.R., Colman, E.G., Rogus, E.M., Sorkin, J.D. and Goldberg, A.P. (1995) Effects of Weight Loss vs Aerobic Exercise Training on Risk Factors for Coronary Disease in Healthy, Obese, Middle-Aged and Older Men: A Randomized Controlled Trial. JAMA, 274, 1915-1921. http://dx.doi.org/10.1001/jama.1995.03530240025035 http://jama.jamanetwork.com/article.aspx?articleid=393276

[20] Wilke, M.S. and Clandinin, M.T. (2005) Influence of Dietary Saturated Fatty Acids on the Regulation of Plasma Cho- 
lesterol Concentration. Lipids, 40, 1207-1213. http://dx.doi.org/10.1007/s11745-005-1487-9

[21] Nakamura, Y., Okuda, N., Turin, T.C., Fujiyoshi, A., Okamura, T., Hayakawa, T., Yoshita, K., Miura, K. and Ueshima, H. (2010) Fatty Acids Intakes and Serum Lipid Profiles: NIPPON DATA90 and the National Nutrition Monitoring. Journal of Epidemiology, 20, S544-S548. http://dx.doi.org/10.2188/jea.JE20090223 http://www.ncbi.nlm.nih.gov/pmc/articles/PMC3920382/

[22] Gender Equality Bureau Cabinet Office, Ed. (2003) White Paper on Gender Equality 2003. Gender Equality Bureau Cabinet Office, Tokyo, 36-37. http://www.gender.go.jp/english_contents/about_danjo/whitepaper/pdf/ewp2003.pdf

[23] Ashida, S., Wilkinson, A.V. and Koehly, L.M. (2012) Social Influence and Motivation to Change Health Behaviors among Mexican-Origin Adults: Implications for Diet and Physical Activity. American Journal of Health Promotion, 26, 176-179. http://dx.doi.org/10.4278/ajhp.100107-QUAN-2

[24] Matthews, C.E., Ainsworth, B.E., Thompson, R.W. and Bassett Jr., D.R. (2002) Sources of Variance in Daily Physical activity Levels as Measured by an Accelerometer. Medicine and Science in Sports and Exercise, 34, 1376-1381.

[25] Berlin, J.E., Storti, K. and Brach, J.F. (2006) Using Activity Monitors to Measure Physical Activity in Free-Living Conditions. Physical Therapy, 86, 1137-1145. http://ptjournal.apta.org/content/86/8/1137.full

[26] Herrmann, S.D., Barreira, T.V., Kang, M. and Ainsworth, B.E. (2014) Impact of Accelerometer Wear Time on Physical Activity Data: A NHANES Semi Simulation Data Approach. British Journal of Sports Medicine, 48, $278-282$. http://dx.doi.org/10.1136/bjsports-2012-091410 http://bjsm.bmj.com/content/48/3/278.long

[27] Koba, S., Tanaka, H., Maruyama, C., Tada, N., Birou, S., Teramoto, T. and Sasaki, J. (2011) Physical Activity in the Japan Population: Association with Blood Lipid Levels and Effects in Reducing Cardiovascular and All-Cause Mortality. Journal of Atherosclerosis and Thrombosis, 18, 833-845. http://dx.doi.org/10.5551/jat.8094 https://www.jstage.jst.go.jp/article/jat/18/10/18_8094/_article

[28] White, K. and Jacques, P.H. (2007) Combined Diet and Exercise Intervention in the Workplace: Effect on Cardiovascular Disease Risk Factors. AAOHN Journal, 55, 109-114.

[29] Bustanji, M.M. and Majali, S. (2013) Effect of Combined Interventions of Diet and Physical Activity on the Perceived and Actual Risk of Coronary Heart Disease among Women in North of Jordan. World Journal of Medical Sciences, 9, 184-189.

http://www.idosi.org/wjms/9(4)13/1.pdf\#search='Effect+of+Combined+Interventions+of+Diet+and+Physical+Activity $\underline{+ \text { on+the+Perceived }+ \text { and }+ \text { Actual+Risk+of+Coronary+Heart+Disease+among+Women+in+North+of+Jordan }}$ 
Scientific Research Publishing (SCIRP) is one of the largest Open Access journal publishers. It is currently publishing more than 200 open access, online, peer-reviewed journals covering a wide range of academic disciplines. SCIRP serves the worldwide academic communities and contributes to the progress and application of science with its publication.

Other selected journals from SCIRP are listed as below. Submit your manuscript to us via either submit@scirp.org or Online Submission Portal.
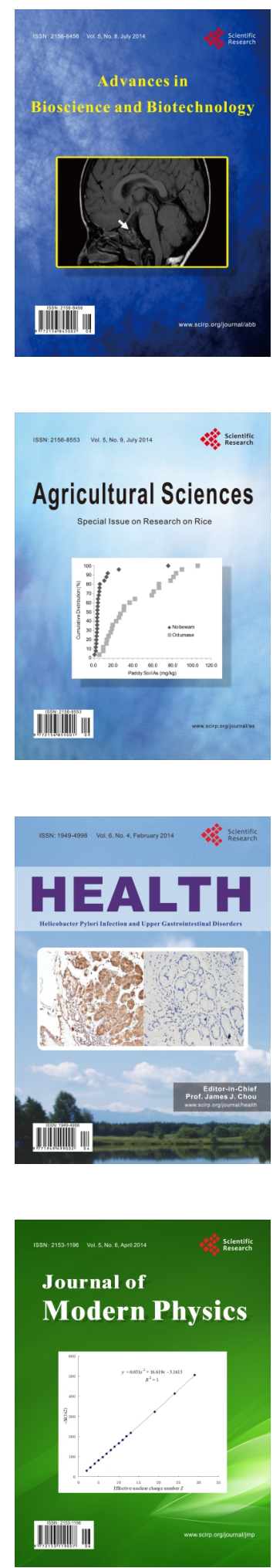
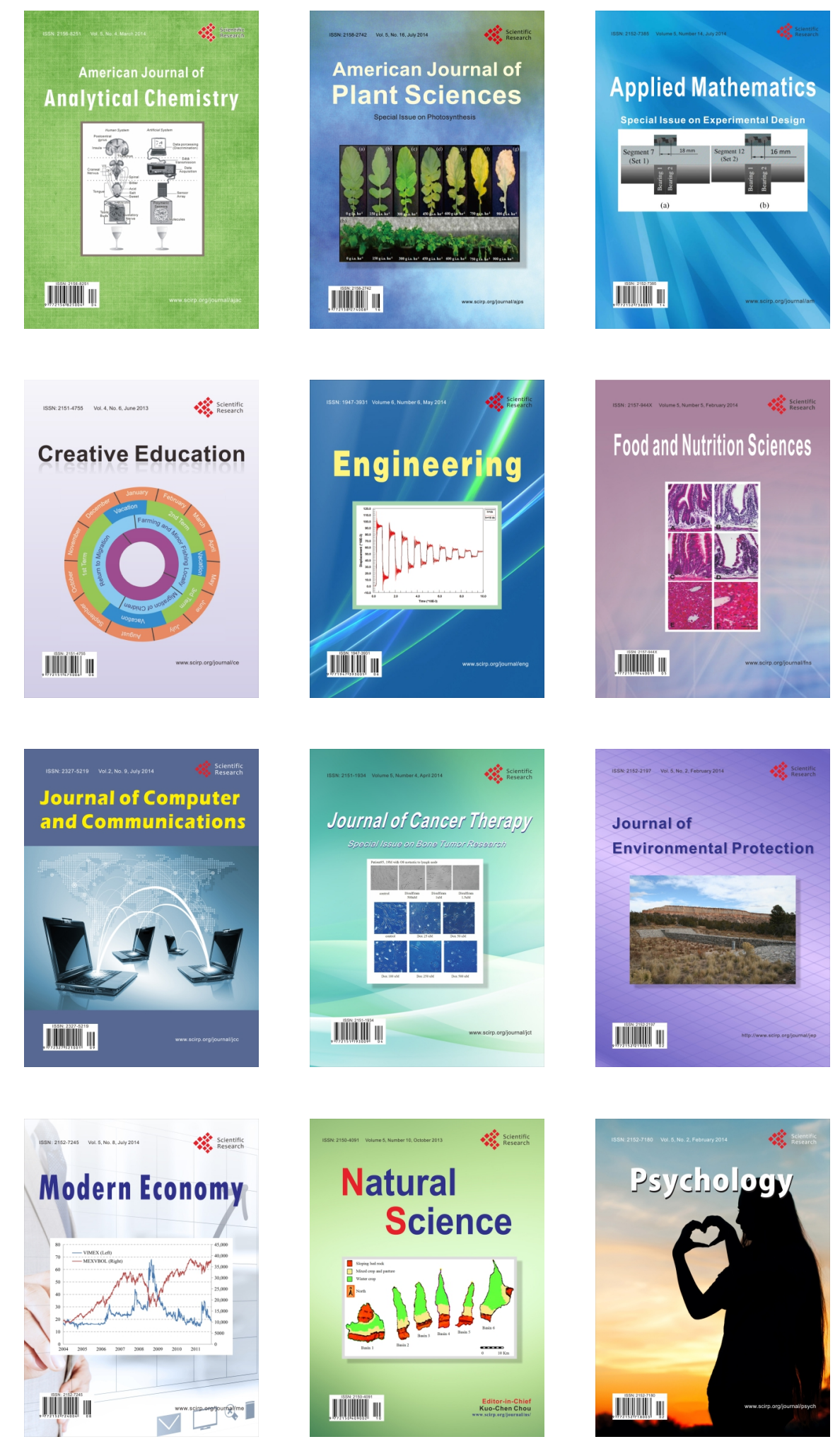